\title{
COMUNICAÇÃO E EFICÁCIA NUMA EQUIPA VIRTUAL: REGRAS E AFINIDADE
}

\begin{abstract}
Resumo: O objectivo deste artigo é mostrar, através da análise de uma equipa virtual internacional, a importância crescente do trabalho colectivo na economia global, bem como a virtualização da cooperação utilizando as TIC como meios de comunicação. No que diz respeito à metodologia, foi adoptada uma abordagem descritiva e exploratória, no qual foram aplicados instrumentos de investigação quantitativa e qualitativa, com especial destaque para a utilização de materiais de fontes primárias, nomeadamente a recolha de mensagens electrónicas trocadas entre os elementos da equipa durante o processo da formação e consolidação da equipa. A análise dos dados sugere que a equipa não conseguiu estabelecer regras formais de comunicação, o que afectou negativamente a eficiência do trabalho, mas em simultâneo foi capaz de superar parcialmente o problema mediante a construção progressiva de afinidade e confiança.
\end{abstract}

Ana Célia Calapez Gomes*, Carla Bianca Dantas Souza Lopes**

PALAVRAS-CHAVE: grupos, equipas, equipas virtuais, comunicação, confiança, afinidade, regras

\begin{abstract}
The aim of this paper is to show, through the analysis of an actual international virtual team, the growing importance of collective work in the global economy, as well as the virtualization of cooperation using ICT's as material providers of communication. Concerning the methodology, a descriptive and exploratory approach was adopted, in which quantitative and qualitative research
\end{abstract}

*Doutora em Gestão, com especialização em Organização e Desenvolvimento de Recursos Humanos - Instituto Superior de Ciências do Trabalho e da Empresa (ISCTE/IUL). Professora Auxiliar da Universidade Atlântica (Barcarena - Oeiras). Email: ana.calapez.gomes@ gmail.com ** Mestre em Gestão com especialização em Recursos Humanos - Universidade Católica Portuguesa, Centro Regional das Beiras (Viseu), Bacharel em Contabilidade, Universidade Estadual de Feira de Santana - Bahia-Brasil. E-mail: acnaibsouz@bol.com.br 
instruments were applied, highlighting in this context the use of primary source material, namely the collection of electronic messages exchanged between team members during the process of team formation and consolidation. The data analysis suggest that the team failed to establish formal rules of communication, which negatively influenced work efficiency, but simultaneously it was able to partially overcome the problem through the progressive building of affinity and trust.

KEYWORDS: groups, teams, virtual teams, communication, trust, affinity, rules.

\section{Introdução}

O fenómeno da globalização, assim como a massificação do uso das chamadas Tecnologias de Informação e Comunicação (TIC) que nele se encontra simbioticamente integrado, despoletou um processo, ainda em curso, de transformação radical dos modelos de organização do trabalho. Tratando-se de um processo extremamente complexo, não cabe no âmbito deste artigo a sua análise aprofundada, mas tão só a referência a duas das suas características mais marcantes, a relevância do trabalho em equipa, e a crescente virtualização dessas mesmas equipas de trabalho. Isto significa que, na economia global, se tornou imprescindível trabalhar colectivamente, pois a justaposição dos esforços individuais não permite a criação das sinergias necessárias quer ao abarcar da complexidade dos problemas, quer à criação de soluções originais e sustentáveis para os ultrapassar. Este é um dos pontos de partida para a tese, segundo a qual, a vantagem competitiva sustentada se obtém a partir da capacidade de juntar e coordenar recursos disponíveis, onde quer que eles se encontrem (Doz et al., 2001). A massificação do uso das TIC permitiu precisamente alargar o espaço de busca destes recursos, possibilitando a formação de equipas que trabalham em comum para realização de projectos, comunicando e construindo trabalho sobretudo com base nas potencialidades oferecidas pela rede virtual. Este facto introduz toda uma nova área de estudo e reflexão, nomeadamente no que diz respeito ao carácter das equipas, às características e problemas próprios da comunicação e a variáveis que, neste universo de tecnologia, são profundamente humanas, como a construção da confiança e a afinidade, ingredientes indispensáveis, não só à concretização de uma comunicação de qualidade, como à eficácia do trabalho colectivo.

O presente trabalho resulta da investigação aprofundada de uma equipa virtual, que se juntou com o objectivo de concretizar um projecto académico. A equipa em causa constitui um bom exemplo tanto da virtualização do trabalho e da comunicação, como da expansão da diversidade, neste caso mais em termos 
nacionais e geográficos, do que linguísticos e disciplinares, e sobretudo da relevância, mas também dos limites dos factores confiança e afinidade. A questão que enforma este trabalho, a da relação dinâmica e interactiva entre regras e afinidade na promoção da eficácia de uma equipa virtual, resulta directamente do estudo empírico desta equipa e do confronto entre as suas práticas e as recomendações teóricas entretanto desenvolvidas por Gold (1997) e Thompsen (2009).

\section{Grupos ou equipas}

A diferenciação entre os conceitos de grupo e equipa é relativamente recente na literatura. Autores dos anos 80 do século XX como Muchelli (1980: 143), por exemplo, não parece estabelecer diferenciação alguma entre os termos, usando-os indiferenciadamente, como se constata quando define equipa como um "pequeno grupo cooperativo motivado por uma tarefa comum, solidário, caracterizado pela unidade, a coesão e o espírito de equipe". Também Campbell (1958) cit. in Mucchielli (1980, p. 143) define equipa de trabalho como um "grupo de indivíduos que são próximos e semelhantes, e que partilham um destino comum nos acontecimentos relativos à tarefa", um grupo em que "os membros são interdependentes no cumprimento de um objetivo comum e percebem essa interdependência (...) Sua motivação é comum; há interações, uma estrutura e uma configuração de papéis complementares" (Mucchielli, 1980, p. 143). Outros autores, mais recentes, preferem enfatizar as diferenças entre os dois conceitos, como se pode constatar quando Lourenço (2005) afirma:

Grupos são uma reunião de pessoas que têm um objetivo comum, porém não necessitam ter um conhecimento das atividades dos companheiros do grupo. No grupo o individualismo impera e o alcance do objetivo traçado pela empresa é a meta do grupo. Já o trabalho em equipe consiste também em um conjunto de pessoas que tem o mesmo objetivo, mas nesse caso, na formação da equipe a sinergia entre os membros é fator decisivo. $O$ conhecimento da atividade de todos os membros é necessária, pois em uma eventual falta, qualquer um poderá substituir o membro ausente. Além do objetivo traçado pela organização, a equipe tende a traçar metas próprias.

Observa-se portanto que o grupo pode ser considerado um sistema social, constituído por elementos que trocam entre si informações e melhores práticas para desenvolver tarefas de responsabilidade individual (Katzenbach \& Smith, 2001, cit. in Bejarano et al., 2006), não existindo responsabilidade colectiva e muitas vezes nem cooperação entre os integrantes no que se refere à produção do trabalho ou produto final. No grupo, o esforço de cada participante é individual, assim como as responsabilidades e os objectivos do trabalho executado. O grupo é estruturalmente adaptado a uma liderança formal, com definições de papéis, 
normas, estatutos, e até com número de elementos mais ou menos estandardizado. A este respeito Minicucci (1987, p. 25) refere que o grupo de trabalho deve ser suficientemente reduzido para permitir que cada um dos membros participe de forma activa nas suas actividades e ao mesmo tempo suficientemente grande para possibilitar um cabal aproveitamento da diversidade de competências nele presentes. No entanto, ainda segundo Mucchielli (1980, p.51), é provável que nos grupos surjam dinâmicas de poder individualizadas e interacções conflituantes, pois apesar da existência de informação compartilhada, a responsabilidade é individual e as competências dos seus participantes diversas e aleatórias.

Quanto à equipa, a palavra tem origem no termo francês équipe, que significa um conjunto de pessoas que se aplicam na realização de uma mesma tarefa ou trabalho. A equipa é caracterizada pelo esforço colectivo e interdependência existente entre seus membros, tanto para o desempenho das funções necessárias ao alcance dos objectivos comuns, como para a partilha de recompensas e responsabilidades. Conforme Katzenbach \& Smith (2001) cit. in Bejarano et al. (2006) os elementos de uma equipa possuem aptidões complementares comprometidas com um objectivo comum, e ainda que cada membro possa ter metas específicas que devem ser atingidas, é o objectivo global a razão de ser da constituição da própria equipa.

Observa-se portanto que o que diferencia de facto a equipa de um grupo é que a execução das actividades realizadas por seus membros dependerá da cooperação dos mesmos, sendo o sucesso da equipa derivado tanto do esforço individual como do esforço conjunto dos seus participantes. Isto exige um grau de comprometimento maior por parte dos seus integrantes, sendo este comprometimento claramente referido por Levin \& $\operatorname{Rad}(2002)$. A solidariedade entre os participantes também é uma das características marcantes da equipa, o que faz com que o nível de desempenho dos seus membros seja maior que a soma dos esforços e talentos individuais. Já com relação aos grupos, a realização do trabalho depende fundamentalmente do esforço de cada um, pois a responsabilidade pelos resultados obtidos é individual. Devido a esta diferenciação é que Giacchetto (2008) considera que a comunicação entre os membros de uma equipa deverá ter uma qualidade superior, sendo as opiniões diferentes estimuladas, e estando os seus membros dispostos a assumir riscos e a apostar no crescimento da equipa e na procura de soluções para os problemas que afetam o seu funcionamento.

Destacando ainda as diferenças entre grupos e equipas, observa-se que numa equipa de trabalho, ao contrário de um grupo não existe a figura do chefe e sim um coordenador ou líder, função desempenhada por indivíduos próximos dos elementos da equipa que, conforme Giacchetto (2008), participam ativamente no trabalho, promovendo uma rica interação entre todos os membros, favorecendo a criatividade e aumentando o respectivo comprometimento mútuo. O líder de uma equipa procura um tipo de liderança compartilhada, fazendo com que todos os 
elementos estejam, de certa forma, preparados para o substituírem quando necessário. Nas equipas, as competências individuais tenderão a ser complementares, ou seja, a insuficiência de um membro é superada pela aptidão dos outros e é devido a estas características que, cada vez mais, os projectos complexos e de grandes dimensões são desenvolvidos por equipas.

\subsection{Equipas virtuais}

As equipas virtuais nada mais são do que uma manifestação da adequação dinâmica dos modelos de organização do trabalho às prerrogativas oferecidas pela massificação do uso das TIC. De acordo com Lipnack \& Stamps (1997a) uma equipa virtual é um tipo de equipa similar às convencionais, que apenas delas difere pela forma como funciona, já que as actividades realizadas pelos seus membros não dependem da localização dos membros no espaço físico, e frequentemente, nem das pertenças organizacionais, nacionais ou linguísticas. A interacção neste tipo de equipas é suportada por meios electrónicos, ou seja, a comunicação faz-se primordialmente através de redes de computadores e telefones, o que permite que o trabalho seja realizado de forma simultaneamente interdependente e interconectada (Polzer, 2004 cit. in Bejarano et al., 2006). Esta constitui a grande inovação das equipas virtuais: a profunda mudança dos conceitos de tempo e espaço, já que frequentemente os membros de equipas virtuais não possuem locais pré-definidos para trabalhar, nem horários rígidos, sendo o contacto entre eles realizado no momento que for acordado e mais oportuno para todos, podendo ser simultâneo ou diferido.

Segundo Harvey \& Drolet (1994), cit. in Bejarano et al. (2006, p. 162-163): As equipas virtuais se estruturam basicamente da mesma forma que todas as equipas desde o início caótico até a formação de um conjunto onde a colaboração e a interdependência são desenvolvidas. Quando atingem a maturidade, as equipes virtuais alcançam entendimento comum de suas metas e prazos de cumprimento destas, têm clara visão da contribuição de todos os membros da equipe, a comunicação entre os membros é fluida e constante, os conflitos são administrados de maneira direta e aberta e os membros sentem-se motivados pelo grupo.

Observa-se através desta citação que o conceito de equipa permanece o mesmo, o que a diferencia na verdade são as suas características próprias e o contexto socioeconómico e tecnológico em que actualmente se inserem. Um momento marcado pela evolução dos meios de comunicação, mediados pelas novas tecnologias de informação e comunicação, que destroem tanto as tradicionais barreiras físicas e geográficas existentes, como os fluxos hierárquicos piramidais, viabilizando uma maior interacção entre os membros das equipas e os respectivos sectores funcionais das organizações, permitindo por exemplo o 
desenvolvimento de projectos com o auxílio das teleconferências e reuniões virtuais. Em verdade, as tecnologias de informação e comunicação tornaram-se fortes aliadas da comunicação entre os membros de equipas virtuais, possibilitando a redução da interacção face-a-face. Trabalhar com ou em equipas virtuais utilizando as tecnologias de informação e comunicação, nas suas várias formas, pode trazer inúmeras vantagens competitivas para as organizações, oferecendo oportunidades ilimitadas de expansão de negócios, tendo membros trabalhando em regiões geograficamente dispersas em período contínuo, diariamente. No entanto, apesar do potencial de expansão e flexibilidade que estas equipas possuem, estruturá-las traz consigo também novos desafios para a área da gestão. Para que haja uma comunicação eficaz entre os membros destas equipas, outros elementos além das tecnologias têm que estar presentes, como a confiança e o entendimento das diferenças pessoais e culturais. Percebe-se portanto que para haver sucesso neste tipo de equipa são necessárias competências tanto humanas quanto tecnológicas, já que as equipas virtuais estão sujeitas a desafios específicos como o aumento da diversidade cultural, maiores dificuldades na comunicação e a distância acrescida entre os seus participantes e tudo isto faz parte das inquietações das equipas virtuais, principalmente as dispersas geograficamente, conhecidas como equipas virtuais globais.

\section{Confiança/afinidade}

$\mathrm{O}$ facto de as equipas de trabalho virtuais estarem completamente dependentes da tecnologia torna-as, quase paradoxalmente, muito mais dependentes ainda de variáveis de relacionamento humano tão subjectivas e ambíguas como a confiança e/ou a afinidade.

Não existe uma definição de confiança universalmente aceite, mas podem-se constatar alguns níveis de convergência em torno deste conceito. De um modo geral, os autores consideram que a confiança se torna particularmente necessária em situações de risco ou incerteza, ou ainda quando os interesses dos agentes não podem ser alcançados sem que haja confiança mútua (Luhmann, 1988, cit. in Sato, 2003, p. 2). Segundo a clássica definição de confiança proposta por Francis Fukuyama (1996, p. 20), esta consiste em "hábitos de natureza ética e em obrigações morais recíprocas interiorizadas por cada um dos membros da comunidade, regras ou hábitos estes que deram a cada um dos membros da comunidade uma base para confiarem uns nos outros". De acordo com o mesmo autor o nível de confiança é muito importante para uma sociedade que deseja ser competitiva, já que o capital social representado pela confiança é tão importante quanto o capital físico (Idem).

Autores mais recentes, como Maxwell (2008b, p. 121) confirmam que a confiança é um dos factores incontornáveis no trabalho em equipa, já que os membros da mesma devem ser capazes de contar uns com os outros sempre que 
necessário. Seguindo a mesma perspectiva, Hardingham (2000, p. 13) expressa que o que faz um grupo de pessoas tornar-se uma equipa é a sensação de confiança existente entre elas. De facto, a confiança passou a atrair uma maior atenção da literatura académica após a década de noventa do século XX "preponderantemente, dos campos da psicologia, da antropologia e da economia" (Novelli, 2005, p. 10). Em termos de gestão organizacional, o tema confiança foi introduzido mais recentemente na área de recursos humanos, onde alguns autores assinalaram a importância do seu papel na estrutura da organização e no processo interactivo, assim como no aperfeiçoamento da competência individual dos trabalhadores (J. Whitney, 1993, cit. in Sato, 2003, p. 2). Esta constatação resulta de algumas análises realizadas sobre a presença de confiança no ambiente de trabalho, em que se observou que ela contribuía para a criação de um clima organizacional mais saudável (Mullins, 2004, p. 347). A valorização da confiança prende-se com toda uma tendência para sobrepor as competências, nomeadamente competências transversais como é o caso da confiança e da cooperação, às qualificações formais na escolha dos colaboradores. A este propósito Júnior (2005, p. 101) não poderia ser mais claro ao afirmar que "acredita-se que as empresas hoje contratam pessoas para trabalhar em seus projectos menos por serem especialistas em suas áreas de actuação do que por estarem imbuídas do conceito de colaboração e confiança". Esta postura enquadra-se perfeitamente nas novas formas emergentes de organização do trabalho, em organizações mais flexíveis, com uma nova estrutura organizativa, que buscam uma gestão mais autónoma, menos burocrática e menos hierarquizada. Para Herzog (2001) cit. in Mariotti (2004, p. 2) essas formas de interacção cooperativas nas organizações têm sido cada vez mais valorizadas e:

Vistas como promissoras para as relações inter e intra-organizacionais na promoção de produtividade e competitividade. São estratégias de ação relacionadas ao entendimento de que sociedades colaborativas, que desenvolvem um alto nível de confiança, tornam-se melhor preparadas para se posicionar estrategicamente e para resistir em contextos econômicos e tecnológicos mutáveis.

As equipas virtuais inscrevem-se nestas novas formas emergentes de organização e de estruturação do trabalho, em que o factor confiança é determinante para a eficácia. De acordo com Charles Handy (s.d.), cit. in Gold (1997) para que no trabalho realizado em ambiente virtual se possa desfrutar de ganhos em eficiência é mais importante empregar o factor confiança do que o controlo. No trabalho virtual a confiança é essencial para que o trabalho seja produtivo, pois a tecnologia por si própria não é suficiente. Lipnack \& Stamps (1997b, p. 16-17) também seguem a mesma linha de pensamento e afirmam que a confiança pode substituir o controlo hierárquico e burocrático em uma equipa 
virtual. Do mesmo modo, Gold (1997) partilha desta opinião considerando o factor confiança como central para o sucesso do trabalho virtual. Observa-se portanto que a confiança é um laço social que, ao se estabelecer, torna menos relevantes os controles formais e burocráticos, revelando-se uma alternativa mais efectiva, e contribuindo directamente para o movimento de adaptação, necessário à sobrevivência das organizações no ambiente competitivo actual (Mariotti, 2004). O mesmo confirmam Zaheer \& Venkatraman, (1999) e Davis et al. (2000), cit. in Novelli $(2005$, p. 16,2005$)$ ao referirem que a "confiança interpessoal, por sua vez, abranda a necessidade de formalização de contratos e reduz ou elimina o controle hierárquico", já que segundo Blanchard (2007, p. 209) "toda liderança genuína é baseada em confiança". Spreitzer \& Mishra (1999) e Grey \& Garsten (2001), ambos referidos por Mariotti (2004) reconhecem a confiança como uma variável crítica que influencia o desempenho, a eficácia e a eficiência das organizações, sobretudo em sectores marcados por intensa competitividade, pois a velocidade e flexibilidade exigem autonomia dos funcionários em todos os níveis da organização, e é nesse contexto que os sistemas tradicionais e burocráticos de controlo se mostram ineficazes para lidar com as necessidades de colaboradores preparados para tomar iniciativas e decisões. É portanto lógico que a questão da confiança surja cada vez mais associada tanto à descentralização, como ao trabalho em equipa (Novelli, 2005). Secretan, (2002), considera mesmo que os elementos da equipa devem compartilhar da "harmonia, confiança, veracidade, respeito, apoio, coragem, química, visão compartida, objetivos e valores" sendo estas características e o senso de compromisso individual e colectivo, o que faz com que uma equipa de alto desempenho possa ser distinguida de outras, já que os membros de uma equipa assumem que seus "compromissos vão além dos objetivos da equipe; existe verdadeira relação de ajuda entre seus membros. Há convicção de que o sucesso e o fracasso serão de todos e dependem de cada um" (Tranjan, 2003, p. 116). Entende-se portanto que a confiança é a base do trabalho em equipa e a mesma é conquistada gradualmente ao longo do tempo e isto através da diminuição da autoproteção de cada um dos seus membros e o aumento da preocupação com o trabalho que se deve realizar em conjunto (Corrêa, 2006). No entanto para que exista confiança e para que a mesma seja aperfeiçoada Blanchard (2007, p. 95) assegura que uma das melhores maneiras "é compartilhar as informações (...) Fornecer informações mais completas às pessoas transmite confiança e uma sensação de que «estamos no mesmo barco»"; e é deste empenho contínuo, segundo Côrrea (2006), que surge a afinidade. A afinidade resulta, por conseguinte, da confiança e, por seu turno, funciona como elemento catalizador da própria confiança, já que esta se desenvolve ao longo do tempo, com base na coerência dos comportamentos (Rodovalho, 2009, p. 88), nomeadamente a observação do cumprimento sistemático de compromissos, o encaminhamento de informações confiáveis para a equipa, as demonstrações de competência, a evidência de interesse sincero pelas opiniões, talentos e envolvimento de outros 
membros da equipa, a emissão de julgamentos ponderados que levam em consideração a diversidade, e o apoio ao trabalho realizado diante de terceiros (Maginn, 1996, p. 71).

A confiança é de tal modo determinante para o trabalho em equipa que Tranjan (2003, p. 116), por exemplo, chega a afirmar que "sem relação de confiança não existe equipe", pois o trabalho torna-se irrealizável. No entanto as relações de confiança estabelecidas entre pessoas e/ou entre organizações são processos extremamente complexos e delicados, por isto devem ser bem geridos e planeados.

\subsection{A construção da confiança}

O modo como a confiança é construída e desenvolvida é um processo que exige intensa dinâmica, já que a confiança tão desejada pelas organizações e pelas equipas de trabalho apresenta algumas peculiaridades interessantes. De acordo com Coleman (1990), Axelrod (1984) e Gambetta (1988), cit. in Sato (2003, p. 9) as "relações de confiança demandam tempo para serem construídas", pois confiança à primeira vista, é realmente improvável e incomum. Em verdade, o elemento tempo é um dos grandes responsáveis pelo crescimento das relações de confiança, já que a mesma é construída gradualmente, por meio do compromisso e responsabilidade recíprocas. Gambetta (1988), cit in Sato (2003, p. 11) considera que a "confiança não é pré-condição para que exista cooperação, e sim é resultado dela, pois baseada em experiências anteriores de cooperação é que a confiança vai sendo construída e fortalecida". Independentemente da forma como se estabelece a relação de confiança, ela assume um papel de extrema relevância que é o de facilitar as relações de trabalho, agilizando e facilitando a execução das actividades e o desempenho geral das equipes e outras organizações. No entanto, a confiança não só tem limites como é uma relação com carácter reversível, ou seja, pode perder-se a qualquer instante se deixar de ser correspondida (Barata, 2008).

\section{Características e desafios específicos da comunicação virtual}

Um dos factores determinantes da construção da confiança e do desenvolvimento de relações de afinidade entre os membros de equipas virtuais é precisamente a qualidade da comunicação. Num passado ainda recente, o trabalho em equipa envolvia interacções presenciais na forma de reuniões e trabalho executado em conjunto, porém com os progressos tecnológicos dos últimos anos, a maior parte das equipas de trabalho tem incorporado alguns elementos de interacção virtual, envolvendo a comunicação não presencial intermediada por $e$ mail, telefone, videoconferência, entre outros meios, fazendo crescente o número de equipas constituídas por membros que se comunicam quase que exclusivamente por meios electrónicos, as chamadas equipas virtuais (Bejarano et 
al., 2006). Nestas equipas a comunicação face-a-face é complementar e, embora nem sempre ocorra, pode contribuir para resolver alguns dos problemas resultantes das características específicas da comunicação virtual. De acordo com Thompsen (2009), a comunicação presencial é extremamente importante para desenvolver o espírito de equipa e a sensibilidade entre os membros, e além disto, é capaz de promover uma melhor performance e cria um ambiente de integração, ao estabelecer entre os participantes deste tipo de equipa uma ligação emocional, embora nem sempre positiva, acabando por reduzir assim os impactos causado pelas barreiras geográficas e/ou organizacionais que os separam e ainda o ruído específico da comunicação virtual. De acordo com o editorial da Harvard Business Review (edição $\mathrm{n}^{\circ} 12,2000$ ) a comunicação virtual utilizada de forma básica pelas equipas virtuais deve possuir três competências: responsabilidade, confiança e adaptabilidade. A comunicação electrónica em uma equipa virtual deve começar pela responsabilidade individual de cada membro, porém este individualismo não pode ser exacerbado, a segunda competência deve ser a confiança, pois para construir um relacionamento eficaz em uma equipa virtual é necessário que se estabeleça uma relação sólida de confiança entre os membros da mesma, sendo sem isto impossível realizar qualquer tipo de trabalho. Segundo Lipnack \& Stamps (1997b, p. 17) as relações de confiança são ainda mais importantes para as equipas virtuais, pois a falta da comunicação face-a-face tende a dificultar o esclarecimento de mal-entendidos. Por este motivo, os mesmos autores (Idem, p. 225) alertam para o facto de uma equipa virtual dever estar sempre atenta ao reforço da confiança em cada estágio de desenvolvimento do trabalho, já que equipas com níveis de confiança mais elevados executam com maior facilidade as suas actividades e organizam o seu trabalho mais rapidamente. A última competência da comunicação virtual referida pelo editorial já citado é a adaptabilidade, ou seja, os membros da equipa devem aprender novas habilidades e adaptar-se ao novo estilo de comunicação utilizada.

A maior parte da comunicação entre os membros das equipas virtuais assume a forma escrita por intermédio de mensagens electrónicas. O simples facto de a comunicação ser fundamentalmente escrita já constitui uma fonte de ruído adicional, pois a falta de comunicação não verbal pode fazer aumentar o grau de ambiguidade do processo de descodificação. Além disto, segundo Levin \& Rad (2002) a maior parte da comunicação numa equipa virtual ocorre de forma assíncrona, ou seja, os seus membros, na maioria das vezes, lêem e interpretam documentos, em tempo diferido em relação ao do seu envio, embora também possa ocorrer uma leitura síncrona. Para Gold (1997) o simples facto do transmissor não receber uma resposta na velocidade em que se deseja, pode ser o suficiente para ocasionar sérios problemas de comunicação. Por este motivo, o mesmo autor afirma que o estabelecimento de um código de conduta para evitar estes tipos de atraso é importante para o sucesso da comunicação em uma equipa virtual de trabalho. Do mesmo modo, interpretar a intenção com que uma 
mensagem foi escrita pode transformar-se num grande desafio, principalmente quando as emoções que estavam presentes ao redigir a mensagem não são percebidas. Para Cunha et al. (2007) o facto de a comunicação ser mediada pelas TIC pode ainda trazer outras dificuldades devido à ausência de pistas sociais na comunicação, como o tom de voz ou a linguagem não-verbal. Os membros das equipas virtuais devem, por conseguinte, adquirir competências também ao nível da explanação escrita de pensamentos e ideias, devido à distância física dos comunicadores. A utilização de símbolos que tentam transmitir sentimentos que podem estar compreendidos no texto que se pretende transmitir pode, neste contexto, facilitar uma mais correcta interpretação das mensagens ${ }^{1}$.

Além deste obstáculo há outros que podem dificultar ainda mais a comunicação, como: a falta de confiança, barreiras pessoais, barreiras institucionais, diversidade geográfica, experiências profissionais e pessoais diversas, além das diferenças quanto aos objectivos individuais. No entanto, por vezes, é o pouco contacto pessoal entre os membros que pode afectar a comunicação, principalmente no que se refere à dinâmica da equipa e à colaboração entre seus membros. Handy (1995), cit. in Cunha et al. (2007, p. 687) explica este facto afirmando que a confiança parte da premissa do contacto face-aface e que "paradoxalmente, quanto mais virtual é a organização, mais as pessoas necessitam de se encontrar pessoalmente". Percebe-se portanto que a comunicação é um factor crítico para uma equipa virtual e, quando ineficaz, constitui uma barreira para o sucesso da mesma.

\subsection{Regra e afinidade na construção da confiança e na eficácia da comunicação}

Segundo alguns autores a criação de regras é de suma importância para aumentar a eficácia da comunicação virtual. Para Gold (1997) as normas e regras são factores determinantes para o sucesso de uma equipa, já que o estabelecimento de um código de conduta, nomeadamente em relação à comunicação, pode evitar diversos problemas decorrentes de causas simples, como o atraso de uma resposta, assim como de factos mais complexos como o uso abusivo e sem produtividade dos meios de comunicação. O ruído na comunicação pode de facto ser sanado e/ou amenizado com a formalização de normas e/ou regras.

Como forma de exemplificar estes tipos de regras Thompsen (2009) destaca: a escolha de métodos de comunicação que melhor se adaptem às necessidades mútuas dos membros da equipa e de cada situação; aplicação de uma tecnologia de comunicação que melhor se aplique às necessidades da equipa e do trabalho realizado; apoio ao uso da tecnologia de comunicação seleccionada para que os

\footnotetext{
${ }^{1}$ Exemplos: :- $)=$ estado de felicidade, ;- ( = estado de tristeza e chorando, :-p = estado sorrindo e mostrando a língua, etc.
} 
membros sintam maior confiança na sua utilização; formulação de objectivos específicos e um planeamento organizado para a utilização das comunicações e verificação da compreensão dos membros da equipa sobre as mensagens transmitidas.

Para Thompsen (2009) a chave do sucesso das equipas de projecto virtual está na comunicação eficaz, porém em situações de distância, para se obter uma comunicação eficaz exige-se uma atenção redobrada na transmissão e recepção das mensagens, sendo significativo o feedback. Além disto, a escolha da tecnologia de comunicação também é extremamente importante, pois será através deste meio que será realizada a maior parte da comunicação entre os membros da equipa virtual. Por isto quanto maior for a gama de opções dos meios de comunicação, mais eficaz pode tornar-se a comunicação nas equipas virtuais, pois a variedade de canais de comunicação pode ajudar os membros da equipa a escolher o meio mais adequado e mais adaptado às suas necessidades, evitando assim inúmeros problemas de comunicação e fazendo com que as mensagens sejam transmitidas de forma mais transparente, eficiente e profunda possível, já que cada meio de comunicação possui diferentes níveis de capacidade.

Quando, por qualquer motivo, inclusive pelo simples facto de que a organização do trabalho em equipas virtuais é um universo relativamente recente, em que os exemplos de boas práticas são incipientes, não abrangentes e insuficientemente analisados e divulgados, não ocorre, ou não se proporciona num contexto específico, a determinação prévia de regras explícitas de comunicação virtual, que possam facilitar o correcto uso das tecnologias e desenvolver a capacidade de tolerância à necessária ambiguidade da comunicação, então será necessário apostar no binómio confiança/ afinidade. Já foi referido, mais acima, que estes conceitos estão perfeitamente interligados, ou seja, o processo de construção de confiança conduz ao desenvolvimento de afinidades, que por seu turno vão potenciar e aprofundar a confiança. É precisamente esta relação dinâmica e complexa entre regra e confiança/ afinidade, e a sua relevância para a eficácia da comunicação em meio virtual que se pretende analisar através do estudo aprofundado de uma equipa que, ao longo de um ano de trabalho conjunto, logrou constituir-se e produzir um projecto de investigação científica ganhador.

\section{$4 \quad$ Uma equipa lusófona}

Um dos primeiros sectores em que se começou a desenvolver o trabalho de equipas virtuais foi o dos projectos de investigação académica. Por motivos vários, que vão desde o interesse de aprendizagem inerente à própria condição de investigador, até às necessidades de carreira e modelos de avaliação individual e organizacional do mundo académico, este tipo de equipas desenvolveu-se, formando redes universitárias e de centros de estudo, unindo cientistas frequentemente geográfica, cultural e linguisticamente muito distantes. Neste 
aspecto, o espaço lusófono não constitui excepção e, desde cedo se estabeleceram políticas específicas de promoção dessa cooperação e intercâmbio entre instituições universitárias de países que têm como língua materna ou oficial o português. A equipa virtual específica estudada teve a sua formação inicial no Brasil através do esforço e dedicação de duas participantes brasileiras, uma delas, proponente e coordenadora da equipa. A equipa foi constituída em 2006, configurando-se como uma rede lusófona reunindo diversas universidades com vista à produção de um projecto de investigação científica em comum. Trata-se, portanto de uma equipa multicultural que integra elementos de três continentes distintos: Africano, Americano e Europeu, e de países como Moçambique, Angola, Brasil e Portugal. A participação feminina é preponderante $(66,67 \%)$. E, como é lógico numa equipa académica, o grau de formação dos membros é elevado, nomeadamente seis doutores, 5 doutorandos, e um mestre. Estiveram envolvidas neste projecto cinco instituições de ensino superior, duas das quais brasileiras, uma moçambicana, uma angolana e uma portuguesa. O estudo realizado concentrou-se em aspectos como a qualidade e eficácia da comunicação virtual, em detrimento do factor intercultural, evidentemente presente, mas desprezado para efeitos da análise efectuada.

Para realização desta investigação foram utilizados vários instrumentos de colheita de dados, um questionário, que visou mensurar dimensões como a coesão da equipa de trabalho e a qualidade da comunicação virtual. Os dados quantitativos obtidos desta forma foram depois cruzados com os qualitativos colectados, quer através da análise textual das mensagens electrónicas trocadas entre os membros da equipa, quer por meio de entrevistas estruturadas. Quanto aos procedimentos de análise dos dados, os mesmos foram recolhidos e analisados de acordo com a sua natureza, sendo utilizada para os questionários a análise estatística simples de distribuição de frequência das respostas, e para a análise das entrevistas e conteúdo textual das mensagens electrónicas uma análise de conteúdo temática que consistiu nos seguintes passos: definição das dimensões em análise - Comunicação e Eficácia; análise categorial, obedecendo à análise temática através de uma classificação progressiva dos dados colectados, com base na teoria analisada; interpretação do sentido das mensagens no seu contexto; codificação das expressões e, por fim, a construção de uma matriz conjunta, das entrevistas e mensagens electrónicas.

\section{Comunicação, ruído e confiança}

Da análise cruzada dos dados resultou que a comunicação virtual foi imprescindível para a eficácia do trabalho realizado por esta equipa, como confirmaram os inquiridos ao afirmarem unanimemente a sua utilização (ver Figura 1, p.86). 


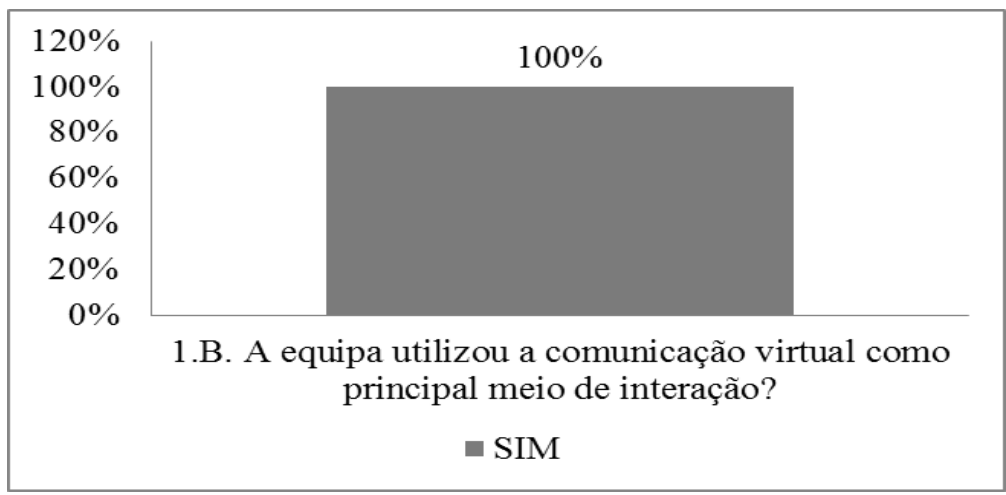

Figura 1 - Comunicação virtual como meio de interação.

Foi através de redes de computadores associados à Internet, que os membros da equipa conseguiram manter um estreito relacionamento entre si, sendo possível por fim elaborar um projecto conjunto. E quando questionados quanto a avaliação do grau de adequação da comunicação virtual (ver Figura 2) a maioria dos inquiridos consideraram a mesma adequada.

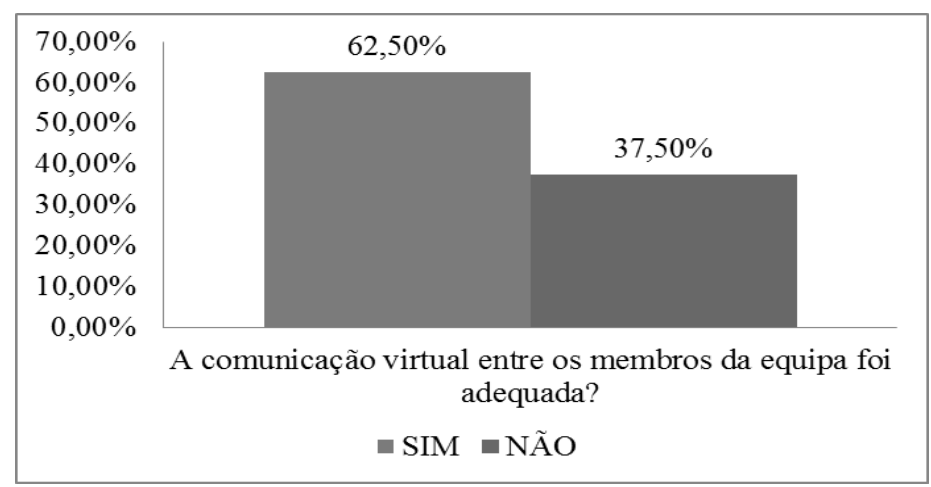

Figura 2 - Avaliação da comunicação virtual.

É importante enfatizar que a qualidade da comunicação em uma equipa virtual é determinante para a eficácia do trabalho realizado pela mesma, por isto um dos objectivos na aplicação do questionário e da entrevista foi apurar o grau da qualidade da comunicação presente na equipa em investigação e de acordo com os dados colectados observou-se que o grau de satisfação quanto à comunicação virtual pode-se dever a diversos factores, como a informalidade do discurso ou o uso da simbologia própria da comunicação virtual, considerados nesta investigação como facilitadores da comunicação. No entanto $37,50 \%$ dos 
membros (ver Figura 2) emitiram opinião negativa quando à suficiência e adequação da comunicação virtual, o que pode estar relacionado com o facto de $50 \%$ dos respondentes não considerarem a comunicação mantida nem directa, nem segura e nem clara (ver Figura 3). De entre os factores que podem ter contribuído para esta avaliação negativa poderá estar a presença de ruído, já que este introduz perturbações indesejáveis na comunicação, podendo provocar perdas de mensagens ou induzir interpretações muito diferentes das pretendidas pelo emissor.

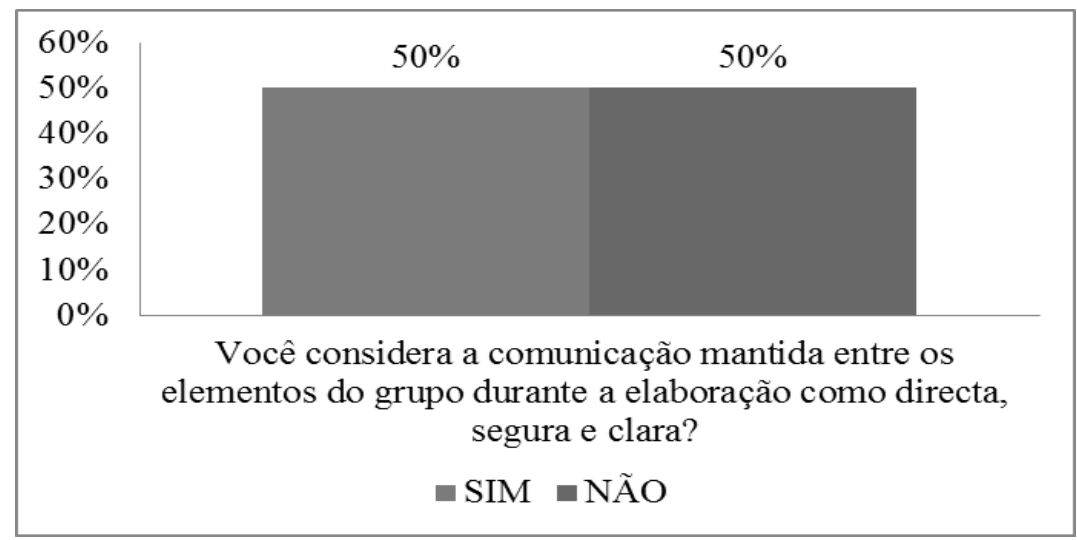

Figura 3 - Avaliação da comunicação mantida entre os membros da equipa.

Como se sabe, a comunicação exclusivamente baseada na escrita é especialmente susceptível ao ruído. O caso em estudo não foge à norma, pois a presença do ruído na comunicação foi significativa (Figura 4). Destaca-se aqui sobretudo o factor "espera de resposta de mensagem ou falta de resposta", o qual obteve a maior expressividade, embora também se tivessem destacado de forma significativa factores de ruído como a "recepção de mensagem atrasada", "mensagens e informações incompletas", "barreiras da comunicação (tecnológicas, físicas, psicologias, entre outras) " e "má interpretação das mensagens". 


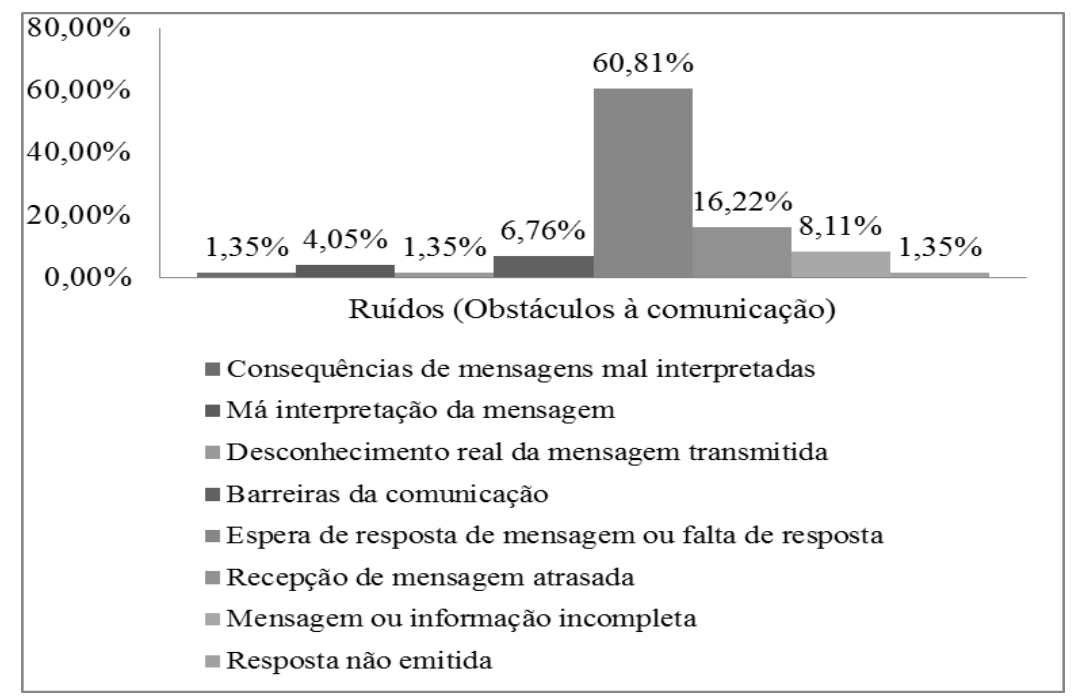

Figura 4 - Desagregação dos vários indicadores do ruído.

A espera de resposta de mensagem, ou a própria falta de resposta e a recepção de mensagem atrasada geraram inúmeras interpretações por parte do emissor, já que no momento que o mesmo encaminha uma mensagem e o receptor não responde atempadamente, o emissor passa a considerar inúmeras hipóteses, desde a falta de interesse por parte do receptor da mensagem, até a consideração de falta de tempo e disponibilidade do mesmo. A análise das mensagens electrónicas e das entrevistas também destacou como factor preponderante de ruído na comunicação "a espera de resposta de mensagem ou falta de resposta", conforme Figura 4. A importância deste factor é em si reveladora de atitudes, pois através dele conseguiu-se observar tanto a insistência e perseverança por parte dos agentes da comunicação, como a falta de compromisso com o trabalho realizado, conforme revelam os seguintes fragmentos: "Até hoje não consegui o termo de compromisso da instituição de ensino, apesar das reiterações"; "Formalizamos o convite, mas ainda não houve a resposta oficial do mesmo"; "Não recebi resposta até agora"; "Não consegui retorno (...) até hoje"; "Vamos esperar a resposta dele". Este ruído pode estar relacionado com a falta de disponibilidade de tempo dos membros da equipa, como pode ser constatado nas citações subsequentes retiradas das entrevistas e mensagens electrónicas: "Ontem estive fora todo o dia, por isso só hoje de manhã vi o teu maill"; "Só agora vi a sua mensagem"; "Só hoje me sentei finalmente para ler e responder aos mails acumulados durante a minha ausência". No entanto, diante dos excertos destacados, apesar dos atrasos, percebe-se um cuidado por parte do receptor em fundamentar o motivo do retardamento da resposta, o que por sua vez também declara o desejo de manter a 
comunicação e construir uma relação de confiança e credibilidade. Aliás, na Figura 5 observa-se claramente que os facilitadores da comunicação ultrapassam largamente os obstáculos promovendo uma melhor comunicação e consequentemente maior proximidade entre os membros da equipa, fazendo com que, em termos gerais, os mesmos avaliassem a comunicação virtual, no fim de todo o processo, como adequada.

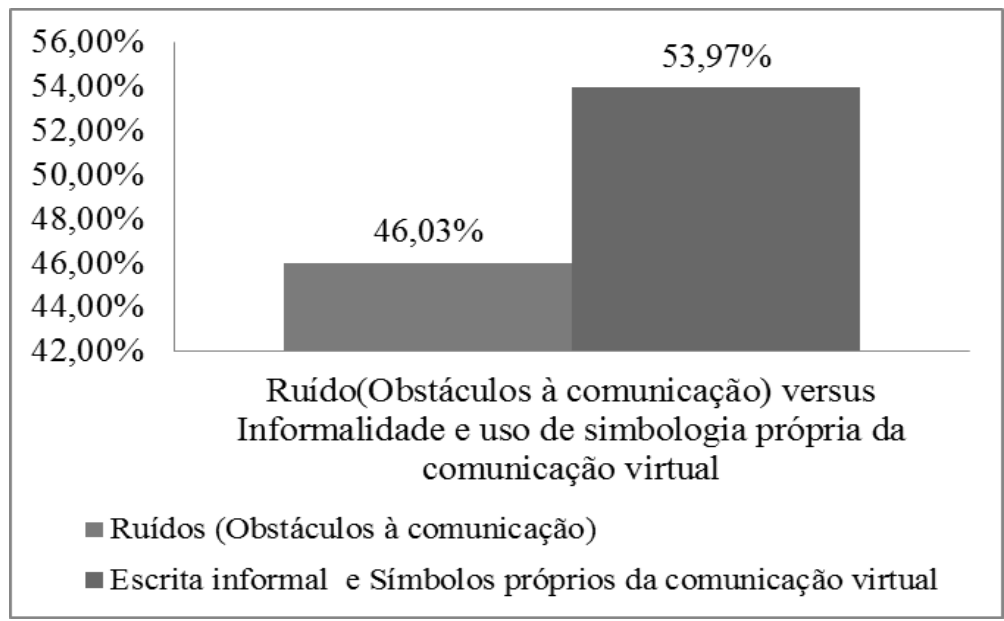

Figura 5 - Ruído (Obstáculos à comunicação) versus Informalidade e uso de simbologia própria da comunicação virtual.

Apesar da presença de obstáculos à comunicação, foi através dela que a confiança entre os membros foi sendo construída. Um processo que, de acordo com o que foi analisado, ocorreu de forma progressiva.

No período de formação da equipa o factor confiança era reduzido (Figura 6), já que de acordo com as respostas obtidas, os inquiridos afirmam que no período de formação da equipa não havia a confiança necessária entre os membros, e mesmo no decorrer do trabalho este factor não era totalmente garantido por todos. Como se pode constatar (Figura 7), as opiniões dividem-se, pois 50\% dos inquiridos consideraram que no decorrer do projecto passou a existir confiança de facto entre os membros, enquanto os outros $50 \%$ discordaram desta mesma opinião. 


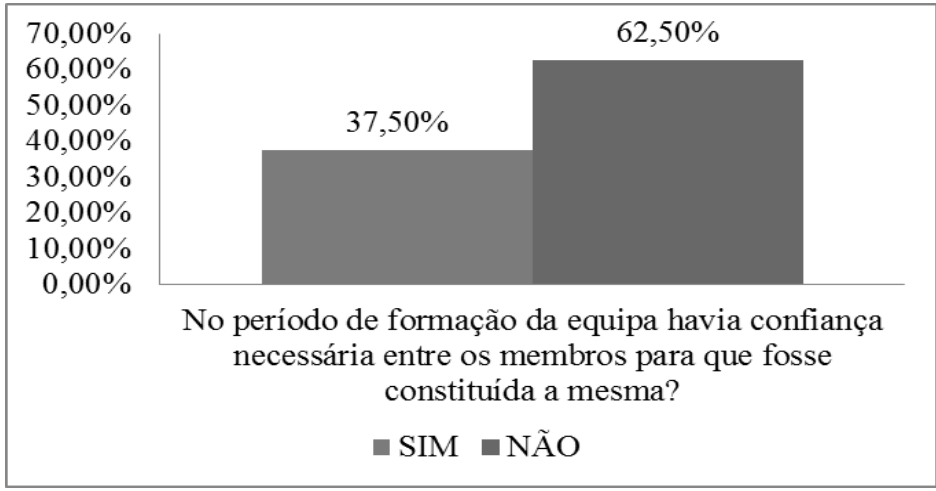

Figura 6 - Factor confiança no período de formação da equipa.

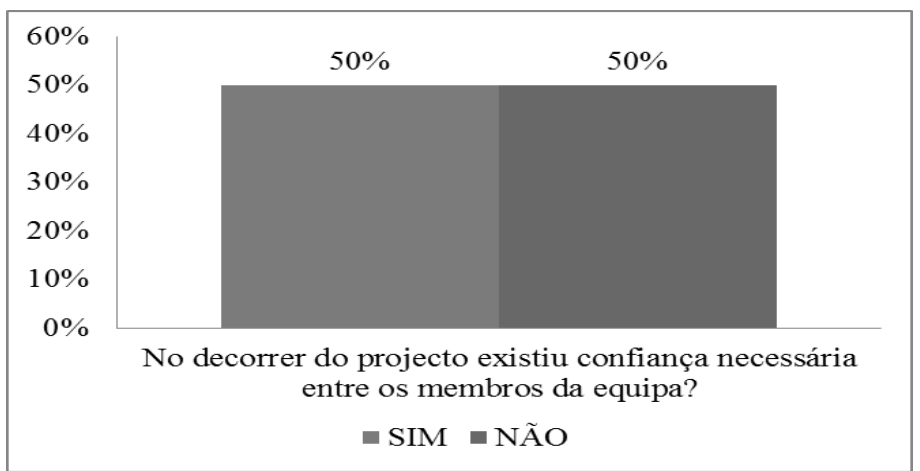

Figura 7 - Factor confiança no decorrer da elaboração do projecto.

No entanto diante desta expressividade, tanto da confiança quanto do grau de desconfiança, optou-se por realizar uma comparação abarcando todo o processo, desde o início da equipa até à aprovação do projecto, verificando-se claramente que a confiança ultrapassou largamente o factor desconfiança (Figura 8). 


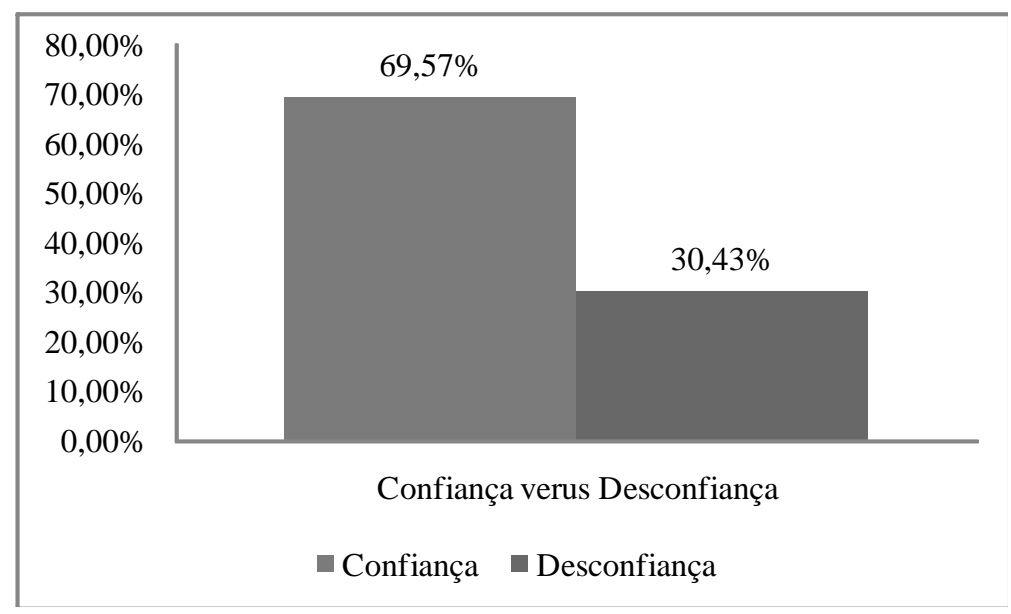

Figura 8 - Confiança versus Desconfiança.

Provavelmente a aquisição gradual do factor confiança foi sendo desenvolvida ao longo do tempo baseada na afinidade devido à sua expressividade na equipa em investigação.

\subsection{Afinidade sem regras}

Diante dos resultados aqui apresentados pode-se constatar o quanto a confiança, associada à afinidade foi imprescindível para o sucesso da equipa em estudo, principalmente no que tange ao desenvolvimento da comunicação dentro da equipa, já que ao serem analisadas as mensagens electrónicas trocadas entre seus membros nota-se a presença da escrita informal, característica da escrita virtual e reflexo da confiança e intimidade que vai surgindo entre os agentes da comunicação - emissor e receptor. A informalidade na escrita demorou um pouco a consolidar-se, mas a sua presença foi de facto inevitável ao longo do tempo, devido à segurança e confiança que foi brotando entre os mesmos, segundo podese observar na Figura 9. 


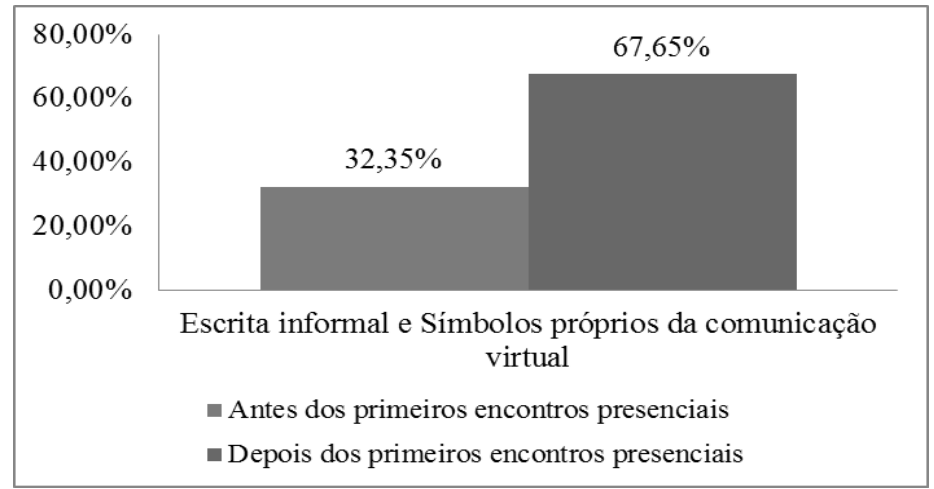

Figura 9 - Escrita informal e Símbolos próprios da comunicação virtual.

Tanto a informalidade na escrita, quanto a utilização de simbologias próprias para este tipo de comunicação são recursos utilizados durante a dinâmica do diálogo em ambiente virtual, como forma de suprir as manifestações discursivas que ocorrem normalmente numa situação de conversa oral face-a-face, ou através de uma conversa telefónica, em que se pode perceber a entoação da voz de quem fala e com quem se fala. A utilização destes recursos tem como objectivo evitar os mal-entendidos, pois até mesmo na conversa face-a-face, muitas vezes os agentes da comunicação, emissor e receptor, não conseguem se fazer entender e no diálogo através da linguagem virtual estes mal-entendidos tendem a ser mais frequentes.

A marca do crescimento desta afinidade pode ser percebida na análise realizada especificamente nas mensagens electrónicas entre o período de 2006 e 2007, período este de formação da equipa e elaboração do projecto. Nas mensagens de 2006, período em que os membros da equipa ainda não se haviam conhecido presencialmente, a informalidade na escrita estava presente em $32,35 \%$ das mensagens electrónicas, já em 2007, período em que houve encontros presenciais, a frequência passou para $67,65 \%$. Descobre-se também através da análise destes dados o quanto foi importante os encontros presenciais para o desenvolvimento da comunicação e da integração entre os participantes, como exemplificado na citação a seguir, recolhida das entrevistas: "O encontro ao vivo e em cores só veio arrematar uma afinidade, respeito e admiração que foram construídos virtualmente". Percebe-se, portanto, que o encontro face-a-face minimizou, de certa forma, os impactos causados pelas barreiras geográficas que separam os elementos deste tipo de equipa de trabalho. 


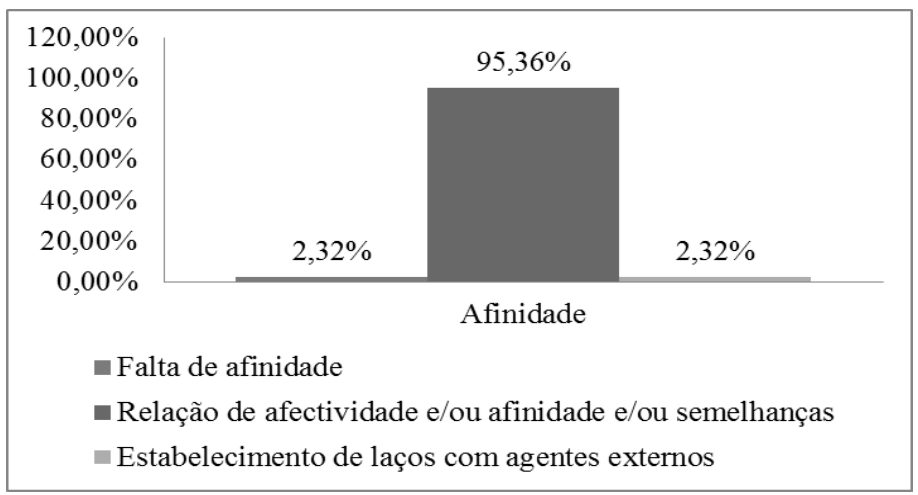

Figura 10 - Afinidade.

Além do desenvolvimento da comunicação, na realização da análise dos dados recolhidos das entrevistas nota-se que a aquisição gradual do factor confiança foi sendo desenvolvida ao longo do tempo baseada também na afinidade, como pode ser comprovado de acordo com citações a seguir: “ (...) penso que isso se deveu a dois factores, primeiro a simpatia imediata conquistada desde a primeira troca de emails, (...) "; "Momentos semelhantes de vida também ajudaram no fortalecimento da confiança, (...) "; "Obrigada pela gentileza em me darem conhecimento do andamento dos contactos (...) "; "Partilhei os conhecimentos pessoais sem restrições"; "Estamos compartilhando conhecimentos em um nível que não necessita cuidados especiais ou restrições necessárias em um contexto de concorrência académica", e como pode ser observado na Figura 10.

Constata-se, no entanto, que o que a equipa conseguiu construir em termos de afinidade faltou em regras, como se pode observar na Figura 11. De acordo com os dados recolhidos através dos questionários, $50 \%$ dos entrevistados afirmaram nunca ter verificado ou sabido do estabelecimento de protocolos ou regras que regulassem o uso e o envio de material entre os membros da equipa, já 37,5\% dos inquiridos afirmaram que estas regras existiram e 12,5\% escolheram não responder a esta questão. 


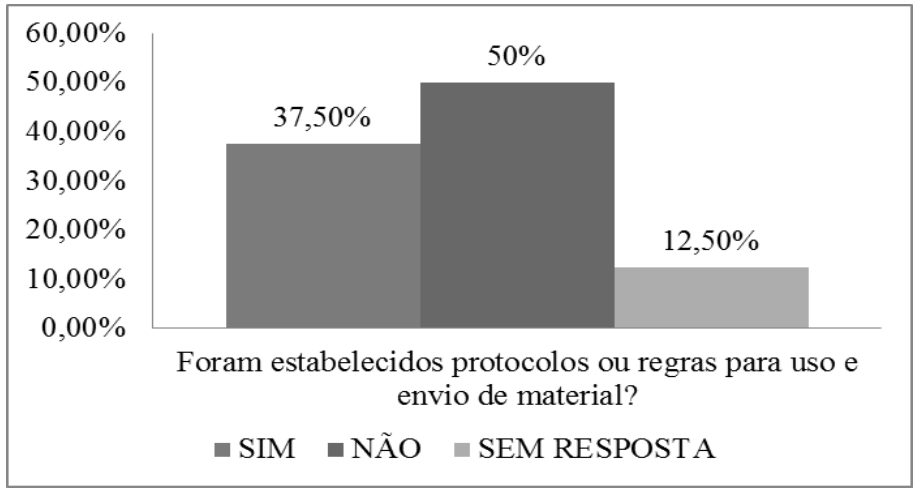

Figura 11 - Estabelecimento de protocolos ou regras.

O mesmo acontece quando se questiona se foram estabelecidas regras quanto ao uso da comunicação electrónica, já que $75 \%$ dos entrevistados certificaram que não foram estabelecidas tais regras (Figura 12).

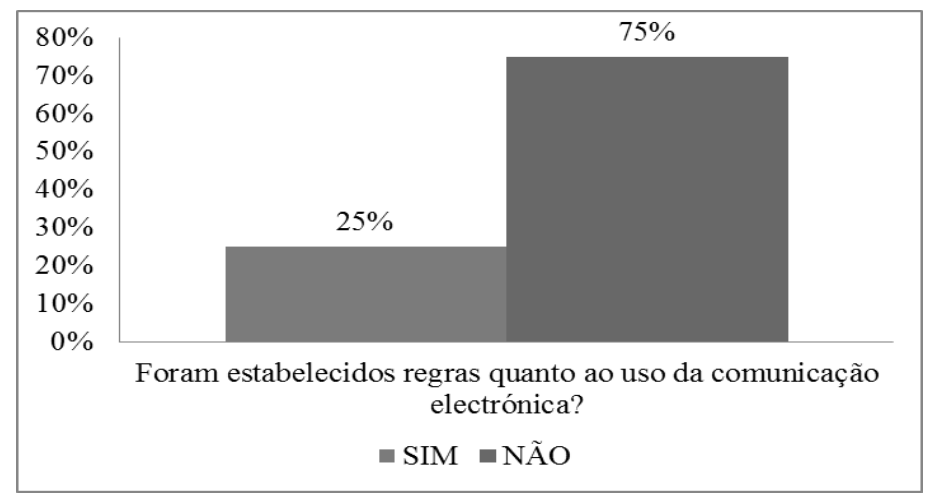

Figura 6 - Estabelecimento de regras quanto ao uso da comunicação electrónica.

Percebe-se diante das declarações dos respondentes que de facto não havia regras pré-definidas, nem definidas quanto ao andamento do trabalho realizado. De facto, a gestão informal adoptada pela equipa obteve sucesso com o trabalho realizado, mais baseada na afinidade do que propriamente em regras, mas esta situação não seria possível manter-se em face do crescimento da equipa e da inerente complexificação das relações, como exemplificada na citação a seguir retirada das entrevistas: “(...$)$, mas assim que a equipa começa a crescer, torna-se difícil geri-la de modo tão informal”. Ou seja, a partir do momento que um grupo tende a crescer, a informalidade e a afinidade deixam de ser suficientes, tornandose a situação insustentável devido à complexidade das relações. É compreensível que as relações pessoais possam substituir as regras, mas só até certo ponto, pois 
compreende-se que para coordenar a acção da equipa teria sido mais fácil se fossem estabelecidas regras, portanto pode-se concluir que o sucesso da mesma, foi de certa forma parcial, já que apesar de ter sido concluído o objectivo comum, que no caso em concreto era a formulação e aprovação do financiamento do projecto, o mesmo ocorreu de forma não tão eficaz como poderia ter sido, se tivessem existido esses meios de regulação do trabalho dos membros, principalmente no que tange à comunicação. Isto leva a concluir que a pequena percentagem de respondentes que afirmaram a existência destas regras e normas, na verdade seguiam individualmente regras próprias ou auto-estabelecidas. Os membros ao reconhecerem automaticamente as dificuldades extra geradas pela distância, passaram a desenvolver práticas que compensassem estes inconvenientes, estando alguns membros sensíveis quanto às diferenças de horário e cultura dos outros membros da equipa. Pode-se considerar que esta atitude decorreu da própria experiência, tanto pessoal quanto profissional dos participantes, pois a maioria dos membros da equipa trabalhavam paralelamente ou já tinham trabalhado em outras equipas virtuais semelhantes à pesquisada.

No entanto, apesar desta falta aparente de regras e normas, diante da análise dos textos das mensagens electrónicas e das entrevistas, é possível perceber um cenário constituído por envolvimento entre os integrantes da equipa, fruto da própria afinidade e confiança que vai sendo criada entre eles, como mostram as seguintes citações: "Caso necessite do meu nome, em termos formais, eu poderei exercer essas funções de orientação e informalmente você poderá acompanhar a orientação da tese de doutoramento (...)"; "Estamos ao dispor para esclarecer qualquer dúvida que tiver com relação ao processo"; "As pessoas que participaram na produção do projecto estavam motivadas por si mesmas", embora o grau de envolvimento variasse bastante, pois nem todos colaboraram da mesma forma "tanto na elaboração do projecto mesmo, auxiliando na redacção, como colocando sua estrutura institucional mais à disposição do projecto".

\section{Conclusão}

A análise efectuada permite concluir que nunca foram de facto estabelecidas regras formais de comunicação no interior da equipa virtual estudada. No entanto, apesar desta falta, a qualidade da comunicação foi positivamente considerada na sua generalidade e constatou-se um processo contínuo de construção de confiança, ainda que a presença de ruído significativo na comunicação possa ter contribuído quer para a lentidão do processo, quer para a sua abrangência relativa, pois uma parte dos membros da equipa nunca chegou a integrar-se completamente no processo.

Diante dos dados obtidos pode-se concluir que o estabelecimento de uma relação de confiança/afinidade entre os participantes permitiu ultrapassar com 
sucesso a ausência das regras, muito embora tenha influenciado negativamente o grau de eficiência do trabalho realizado e, eventualmente, a continuidade da equipa. 


\section{Referências}

BARATA, A. (2008). A construção da confiança - Teoria dos Jogos e Ética. Consultado em 15 de Fevereiro de 2010. Disponível em URL: «http://www.lusosofia.net/textos/andre_barata_construcao_confianca_teoria_ dos_jogos_etica.pdf»

BEJARANO, V. C. et al. (2006). Equipes virtuais - um estudo de caso na indústria têxtil norte-americana. Consultado em 2 de Março de 2009. Disponível em URL: «http://www.scielo.br/pdf/prod/v16n1/a13v16n1.pdf».

BLANCHARD, K. (2007). Liderança de alto nível - como criar e liderar: organizações de alto desempenho. Editora: Bookman

CORRÊAA, S. L S. (2006). Liderando o crescimento. Consultado em 22 de Fevereiro de 2010. Disponível em URL: «http://www.administradores.com.br/artigos/liderando_o_crescimento/1277 $6 / \gg$

CUNHA, M. P. et al. (2007). Manual de estudos organizacionais: temas de psicologia, psicossociologia e sociologia das organizações. Lisboa: Editora RH.

DOZ, Y; Santos, J.; Williamson, P. (2001) From Global to Metanational: How Companies Win in the Knowledge Economy. Boston: Harvard Business School Press.

FUKUYAMA, F. (1996). Confiança: valores sociais e criação de prosperidade. Publicação Lisboa: Gradiva.

GIACCHETTo, C. P. (2008). Grupo X Equipe. Consultado em 9 de Setembro de 2009. Disponível em URL: «http://www.administradores.com.br/artigos/grupo_x_equipe/ $25857 / \gg$.

GOLD, D. (1997). Leading Virtual Teams. Consultado em 15 de Abril de 2009. Disponível em URL: «http://www.seanet.com/ daveg/ltv.htm»

HARDINGHAM, A. (2000). Trabalho Em Equipe. Coleção: VOCE S.A. Editora: Nobel.

Harvard Management Communication Letter (2000). Communicating with Virtual Project Teams/Creating Successful Virtual Organizations - Virtual

Communication, vol. $3, \mathrm{n}^{\circ} 12$. Consultado em 2 de Abril de 2009. Disponível em URL: «http://hbswk.hbs.edu/archive/2122.html».

JUNIOR, R. R. (2005). Competências e maturidade em gestão de projetos: uma perspectiva estruturada. Editora Annablume.

LEVIN, G. \& Rad, P. (2002). Key People Skills for Virtual Project Managers. Consultado em 15 de Abril de 2009. Disponível em URL: 
«http://www.allpm.com/modules.php?

op=modload\&name $=$ News\&file=article \&sid $=440 »$.

LIPNACK, J. \& Stamps, J. (1997a). Virtual Teams: Reaching Across Time, Space and Organizations. Consultado em 15 de Abril de 2009. Disponível em URL: «http://www.effectivemeetings.com/technology/virtualteam/lipnackstamps.as p».

LIPNACK, J. \& Stamps, J. (1997b). Virtual Teams: Reaching Across Space, Time and Organizations with Technology. Consultado em 5 de Setembro de 2009. Disponível em URL: «http://www.netage.com/pub/books/download.html».

LOURENÇO, R. B. (2005). Um por todos, todos por um e todos por todos. Consultado em 9 de Setembro de 2009. Disponível em URL: http://www.administradores.com.br/artigos/um_por_todos_todos_por_um_e_ todos_por_todos/11440/

MAGINN, M. D. (1996). Eficiência no trabalho em equipe. Editora: Nobel.

MARIOTTI, D. F. (2004). Confiança e Desempenho Organizacional: Um estudo de caso em uma empresa do sector de agronegócios. Consultado em $22 \mathrm{de}$ Fevereiro de 2010. Disponível em URL: «http://bdtd.unisinos.br/tde_busca/arquivo.php?codArquivo=39»

MAXWELL, J. C. (2008a). Minutos de liderança. Editora: Thomas Nelson Brasil.

MAXWELL, J. C. (2008b). As 17 incontestáveis leis do trabalho em equipe. Editora: Thomas Nelson Brasil.

MINICUCCI, A. (1987). Técnicas do trabalho de grupo. São Paulo: Atlas.

MUCCHIELLI, R. (1980). O trabalho em equipe. São Paulo: Martins Fontes.

MULLINS, L. J. (2004) Gestão da hospitalidade e comportamento organizacional. Editora Bookman

NOVELLI, J. G. N. (2005). Confiança interpessoal na sociedade de consumo. Editora: Annablume

RODOVALHO, R. (2009). O líder que faz a diferença. Editora: Thomas Nelson Brasil.

SATO, C. T. (2003). Gestão baseada em relações de confiança. In: RAEeletrônica, vol. 2, $\mathrm{n}^{\circ}$ 1. Consultado em 20 de Fevereiro de 2010. Disponível em URL: «http://www16.fgv.br/rae/artigos/1875.pdf»

SECRETAN, L. H. K. (2002). Um nível acima: construindo organizações que estimulem a excelência. Editora: Cultrix.

THOMPSEN, J. A. (2009) Leading Virtual Teams. Consultado em 06 de Setembro de 2009. Disponível em URL:

«http://www.qualitydigest.com/sept00/html/teams.html».

TRANJAN, R. A. (2003). Empresa de corpo, mente e alma, a: como obter melhores resultados com equipes. Editora: Gente, São Paulo. 